\title{
Initial pain management plans in response to severe pain indicators on oncology clinic previsit questionnaires
}

\author{
Michael S Sanatani MD FRCPC ${ }^{1,2}$, Maan Kattan MBBS FRCPC ${ }^{3,4}$, Dwight E Moulin MD FRCPC ${ }^{2,5}$
}

\begin{abstract}
MS Sanatani, M Kattan, DE Moulin. Initial pain management plans in response to severe pain indicators on oncology clinic previsit questionnaires. Pain Res Manag 2014;19(6):309-312.
\end{abstract}

BACKGROUND: The issue of how to address patient pain in the outpatient setting remains challenging. At the London Regional Cancer Program (London, Ontario), patients complete the Edmonton Symptom Assessment System (ESAS) before most visits.

OBJECTIVES: To perform a chart review assessing the frequency and, if applicable, the type of a clinical care plan that was developed if a patient indicated pain $\geq 7$ on a 10 -point scale.

METHODS: The charts of 100 eligible sequential outpatient visits were reviewed and the initial pain management approaches were documented. RESULTS: Between December 2011 and May 2012, visits by 7265 unique patients included 100 eligible visits (pain $\geq 7$ of 10 ). In 83 cases, active pain management plans, ranging from counselling to hospital admission, were proposed. Active pain management plans were more likely if the cause was believed to be cancer/treatment related: 63 of 65 (96.9\%) versus 20 of 35 ( $57.1 \%$, noncancer/unknown pain cause); $\mathrm{P}<0.001$. There were no differences depending on cancer treatment intent or medical service.

CONCLUSIONS: Active pain management plans were documented in $83 \%$ of visits. However, patients who reported severe pain that was assessed as benign or unknown in etiology received intervention less frequently, perhaps indicating that oncologists either consider themselves less responsible for noncancer pain, or believe that pain chronicity may lead to a higher ESAS pain score without indicating a need for acute intervention. Further study is needed to determine the subsequent effect of the care plans on patient-reported ESAS pain scores at future clinic visits.

Key Words: Analgesia; Assessment; Cancer pain; Electronic patient record; Screening

\section{Des plans de gestion initiale de la douleur en réponse à des indicateurs de douleur intense dans des questionnaires avant la visite à la clinique d'oncologie}

HISTORIQUE : Il est toujours difficile de soulager la douleur des patients en milieu ambulatoire. Au programme régional sur le cancer de London, en Ontario, les patients remplissent l'échelle ESAS d'évaluation des symptômes d'Edmonton avant la plupart des visites.

OBJECTIFS : Effectuer un examen des dossiers pour évaluer la fréquence et s'il y a lieu, le type de plan de soins cliniques élaboré si le patient déclarait une douleur d'au moins sept sur une échelle de dix points.

MÉTHODOLOGIE : Les chercheurs ont examiné les dossiers de 100 visites séquentielles de patients admissibles en milieu ambulatoire et consigné les approches initiales de gestion de la douleur.

RÉSULTATS : Entre décembre 2011 et mai 2012, 100 des 7265 visites uniques de patients étaient admissibles (douleur d'au moins sept sur dix). Dans 83 cas, des plans de gestion active de la douleur oscillant entre des conseils et une hospitalisation étaient proposés. Ces plans étaient plus probables si on croyait la cause liée au cancer ou au traitement : 63 sur $65(96,9 \%)$ plutôt que 20 sur $35(57,1 \%$, cause non cancéreuse ou d'origine inconnue); $\mathrm{P}<0,001$. Il n'y avait pas de différences selon l'intention de traiter le cancer ou le service médical.

CONCLUSIONS : Les plans de gestion active de la douleur étaient inscrits au dossier de $83 \%$ des visites. Cependant, on intervenait moins auprès des patients qui déclaraient des douleurs intenses dont l'étiologie était évaluée comme bénigne ou d'origine inconnue. Ainsi, les oncologues se considéraient peut-être comme moins responsables des douleurs non cancéreuses ou croyaient peut-être qu'une douleur chronique s'associait à un indice de douleur élevé sur l'échelle ESAS ne nécessitant pas d'intervention rapide. D'autres recherches s'imposent pour déterminer l'effet subséquent des plans de soins sur les résultats de la douleur déclarée par les patients d'après l'échelle ESAS lors de futures visites à la clinique.

examination and diagnostic tests) was not related to patient-reported pain relief at subsequent visits. Another study demonstrated that providing physicians with a summary of a patient's self-reported pain assessment on a paper sheet on the clinic chart, to be reviewed before a patient visit, led to an increase in analgesic prescription changes, but $35 \%$ of the patients were still deemed to have received inadequate treatment (7). Further research is required to define and optimize the key aspects of the pain management process, and the first step is to assess the health care team's response to the patient's report of being in pain. To our knowledge, this has not previously been studied.

The 2011 Cancer Care Ontario guideline for cancer-related pain management recommends at least screening for pain at each patient visit (8). At the London Regional Cancer Program (LRCP), all patient visits now include the initial completion of the Edmonton Symptom found that the number of pain elements assessed (of the complete of screening, history, functional enquiry, psychosocial enquiry, physical

${ }^{1}$ Department of Oncology, University of Western Ontario; ${ }^{2}$ London Regional Cancer Program, London, Ontario; ${ }^{3}$ Department of Anesthesiology, King Abdulaziz Medical City; ${ }^{4}$ Teaching Faculty, King Saud Bin Abdulaziz University for Health Sciences, King Abdulaziz Medical City, College of Medicine, Jeddah, Saudi Arabia; ${ }^{5}$ Departments of Clinical Neurological Sciences and Oncology, University of Western Ontario, London, Ontario Correspondence: Dr Michael S Sanatani, Department of Oncology, University of Western Ontario, London Regional Cancer Program,

790 Commissioners Road East, London, Ontario N6A4L6. Telephone 519-685-8640, fax 519-685-8624, e-mail michael.sanatani@lhsc.on.ca 
TABLE 1

Patient characteristics $(n=100)$

\begin{tabular}{lc}
\hline Characteristic & Patients, $\mathbf{n}$ (total $\mathbf{n = 1 0 0 )}$ \\
\hline Sex & \\
Male & 40 \\
Female & 60 \\
Primary disease & \\
Lung & 16 \\
Breast & 21 \\
Colorectal & 10 \\
Prostate & 9 \\
Kidney & 4 \\
Bladder & 2 \\
Uterus & 2 \\
Cervix & 1 \\
Pancreas & 1 \\
Head and neck & 10 \\
Neuroendocrine & 13 \\
Skin & 2 \\
Peritoneal & 2 \\
Gallbladder & 2 \\
Unknown & 1 \\
Brain & 4 \\
ESAS pain score (0-10) & 1 \\
7 & 27 \\
8 & 27 \\
9 & \\
10 & 27 \\
\hline
\end{tabular}

ESAS Edmonton Symptom Assessment System

Assessment System (ESAS) (9) via an electronic kiosk, which includes a pain scale (0 to 10$)$ visible to the nurse and physician on the patient's electronic record before they meet the patient in the clinic.

The purpose of the present study was to document the types of clinical care responses prompted by patient report of severe pain in the electronic medical record to assess the incidence of new active pain management plans, in the context of a quality assurance review. As an exploratory analysis, we also intended to analyze any correlation between the active care management plans and the specialty of the physicians, the assumed cause of the pain or the cancer treatment intent. Based on survey data already published (2-5), our expectation for the present study was that the commencement of an active pain management plan would occur at $<60 \%$ of visits at which patients reported pain $\geq 7$ of 10 .

\section{METHODS}

The patient medical record (both electronic and paper contents) was reviewed for 100 sequential unique patient visits, starting December 15, 2011, at solid tumour medical, surgical and radiation oncology clinics at the LRCP, at which the patient documented a pain level $\geq 7$ of 10 at the electronic kiosk before seeing the nurse and physician. Patient visit identification was performed by a search of the electronic hospital records starting with the first visit registered at the LRCP at 08:00 December 15, 2011 and searching forward, screening first by severe ESAS pain level, and then by inclusion criteria and exclusion criteria, until 100 eligible visits were found. The total number of sequential visits that had to be screened electronically to find 100 ESAS pain scores of $\geq 7$ in the target population was also documented.

The ESAS is a standardized symptom assessment screening tool consisting of 10 individual visual analogue scales (for the symptoms of pain, tiredness, nausea, depression, anxiety, drowsiness, appetite, wellbeing and shortness of breath, and one blank item that the patient can add). Zero indicates absence of the symptom and 10 represents the highest intensity of that symptom the patient has experienced to date in their life. A score of $\geq 7$ is considered to be severe (10).
The ESAS scores are automatically added to the electronic patient record and appear beneath the laboratory results on the same screen, for viewing by the physician or nurse. However, at the time of the present study, severe ESAS scores $(\geq 7)$ were not highlighted (they have since been made to appear in bright red as a 'critical' value).

Patients attending the palliative care or pain management clinics were excluded because, by definition, patients attending these clinics had been specifically referred for review of an active pain management plan, and the present study was focused on examining the behaviour of oncologists concerning the initial screening pain assessments. Visits for administration of chemotherapy or radiation without physician involvement, and urgent visits to the ambulatory care bay for dehydration, transfusions, electrolyte imbalances or other acute issues for which, at the LRCP, an ESAS questionnaire is not completed were also excluded.

Once the eligible visits were identified, the paper and full electronic charts were reviewed for that visit. All 100 visits were for unique patients (there was not more than one eligible visit per patient included). Patient care was categorized into the following types of initial pain management plans (more than one could apply to one visit):

- No mention of pain symptom in nursing or physician assessments;

- Documentation of pain or severity but no change to management;

- Investigation ordered related to pain symptom;

- Counselling about existing pain control regimen or follow-up arranged, without change to prescription;

- Dose adjustment in pain medication prescription;

- Change in pain medication prescription (new agent, formulation and/or route of administration);

- Referral to specialized pain consultant or clinic (pain, palliative care, neurology);

- New oncology treatment modality decision or referral including radiation, systemic anticancer treatment or surgical treatment;

- Referral to other physician for pain management (except as in the two abovementioned points);

- Inpatient admission for pain crisis management.

In addition, demographic information was collected including age, sex, primary site of tumour, treatment intent, current cancer treatment (if applicable), pain causality documented (cancer related, treatment related, noncancer cause, unknown) and the most responsible service of visit (medical oncology, radiation oncology, surgical oncology).

The primary end point of the analysis was the proportion of patients reporting pain $\geq 7$ who received an intervention aimed at pain management (the latter seven points), any of which were considered to be an active pain management plan because these plans include some form of action on the part of the physician directly aimed at improving the pain level, beyond ordering investigations.

As secondary end points, correlations among the primary end point and the perceived cause of the pain (cancer related versus noncancer related), the oncological treatment intent (curative versus palliative) and the physician specialty (medical, radiation or surgical oncology) were explored.

Approval for the study was provided through the Human Subjects Research Ethics Board REB \#18731E at the University of Western Ontario, London, Ontario. $\chi^{2}$ analysis was used for exploratory correlational analyses.

\section{RESULTS}

Starting December 15, 2011 and ending May 31, 2012, a total of 16734 sequential visits by 7265 patients were analyzed electronically to find 100 unique patient visits ( $1.3 \%$ of 7265 patients) in which patients indicated ESAS pain scores of $\geq 7$. Patient demographic characteristics and disease data are presented in Table 1.

Table 2 shows the pain management plans for all the patient visits, as well as the further analyses according to pain diagnosis, medical specialty and cancer treatment intent. For the 100 visits, a total of 149 pain care plans were undertaken. Table 3 shows the number of 
TABLE 2

Pain management plans ( $n=149$ plans)

\begin{tabular}{|c|c|c|c|c|c|c|c|c|}
\hline \multirow{2}{*}{$\begin{array}{l}\text { Care response (more than one } \\
\text { per visit possible) }\end{array}$} & \multirow{2}{*}{ All visits } & \multicolumn{2}{|c|}{ Cause of pain } & \multirow{2}{*}{\multicolumn{3}{|c|}{ Specialty of physician (oncology) }} & \multirow{2}{*}{\multicolumn{2}{|c|}{ Cancer treatment }} \\
\hline & & $\begin{array}{l}\text { Cancer or } \\
\text { treatment }\end{array}$ & $\begin{array}{l}\text { Unknown or } \\
\text { noncancer }\end{array}$ & & & & & \\
\hline No mention of pain & 2 & 1 & 1 & 0 & 2 & 0 & 2 & 0 \\
\hline Investigation ordered & 7 & 3 & 4 & 4 & 2 & 1 & 5 & 2 \\
\hline Pain management counselling & 38 & 28 & 10 & 21 & 16 & 1 & 18 & 20 \\
\hline Analgesic dose change & 14 & 14 & 0 & 11 & 3 & 0 & 5 & 9 \\
\hline Pain specialist referral & 19 & 12 & 7 & 9 & 10 & 0 & 7 & 12 \\
\hline New treatment modality & 26 & 24 & 2 & 15 & 8 & 3 & 8 & 18 \\
\hline $\begin{array}{l}\text { Referral to physician (other than } \\
\text { pain clinic) for pain treatment }\end{array}$ & 7 & 3 & 4 & 2 & 4 & 1 & 3 & 4 \\
\hline Inpatient admission & 2 & 1 & 1 & 2 & 0 & 0 & 0 & 2 \\
\hline Total & 149 & 100 & 49 & 84 & 58 & 7 & 67 & 82 \\
\hline
\end{tabular}

TABLE 3

Incidence of active pain management plans ( $n=100$ visits)

\begin{tabular}{|c|c|c|c|c|c|c|c|c|c|c|c|}
\hline \multirow[b]{3}{*}{ Pain management plan } & \multirow{3}{*}{$\begin{array}{c}\text { All } \\
\text { visits }\end{array}$} & \multicolumn{3}{|c|}{ Cause of pain } & \multirow{2}{*}{\multicolumn{4}{|c|}{ Specialty of physician (oncology) }} & \multirow{2}{*}{\multicolumn{3}{|c|}{ Cancer treatment }} \\
\hline & & \multirow{2}{*}{$\begin{array}{l}\text { Unknown or } \\
\text { noncancer }\end{array}$} & \multirow{2}{*}{$\begin{array}{l}\text { Cancer or } \\
\text { treatment }\end{array}$} & \multirow[b]{2}{*}{$\mathbf{P}$} & & & & & & & \\
\hline & & & & & Medical & Radiation & Surgical & $\mathbf{P}$ & Curative & Noncurative & $\mathbf{P}$ \\
\hline $\begin{array}{l}\text { No mention of pain, documenting } \\
\text { only, or only investigation ordered }\end{array}$ & 17 & 15 & 2 & & 9 & 7 & 1 & & 11 & 6 & \\
\hline Active management plan & 83 & 20 & 63 & $<0.001$ & 49 & 30 & 4 & NS & 37 & 46 & NS \\
\hline Total & 100 & 35 & 65 & & 58 & 37 & 5 & & 48 & 52 & \\
\hline
\end{tabular}

NS Not significant

visits in which an active pain care plan was made (primary end point). In $83(83 \%)$ visits, the care response indicated an active pain management plan ranging from analgesic counselling to inpatient admission for pain crises. There was a significantly higher chance of an active plan (counselling or more) in patients with cancer or treatmentrelated pain relative to pain that was noncancer related or of unknown cause ( 63 of 65 [96.9\%] versus 20 of 35 [57.1\%]; P<0.001). No correlation was found between care plan and physician specialty or treatment intent (Table 3). Many visits resulted in more than one care response (149 responses at the 100 visits), with counselling, new treatment modality and pain clinic referral being the most common responses.

\section{DISCUSSION}

In the present study, contrary to our expectations, counselling or more active pain management plans occurred in a high proportion (83\%) of visits to the LRCP when patients reported their pain to be $\geq 7$ on a 0 to 10 scale. This rate was even higher in the subgroup of patients with cancer-related or treatment-related pain (96.9\%), but significantly lower in those patients believed to have noncancer pain or pain of unknown etiology (57.1\%).

The overall prevalence of pain rated at $\geq 7$ of 10 was quite low ( $1.3 \%$ of patients) in the time frame studied. However, it must be acknowledged that patients being seen at palliative care or pain management clinics in the centre were excluded from the present study for reasons outlined above; therefore, the sample likely only represents patients whose severe pain was relatively recent in onset because a certain proportion of patients with severe pain are eventually referred on to specialty clinics (eg, 19\% of the patients in our study window). Also, at our institution, patients receiving chemotherapy or radiotherapy are not asked to complete the ESAS at the treatment visits. This may be a lost opportunity for screening for symptoms occurring between physician visits.

Despite these generally encouraging results in the oncology clinics, several concerns must be raised. The use of a screening tool alone for assessment of the complex symptom of pain with little evidence of a detailed pain assessment is problematic. A more detailed assessment may, in fact, subsequently have occurred during the patient-physician or patient-nurse interaction, but physician documentation was generally believed to be rather limited, although we did not formally evaluate this in our study. Chisholm et al (11), in their study investigating observed versus documented physician assessment of pain, made a similar observation. However, adding a more comprehensive pain assessment tool to the electronic screen may also not be the answer. Bainbridge et al (12) noted that there is a large variation in how physicians note the ESAS scores provided during a clinical encounter, with only $55 \%$ of physicians reporting they review it "most of the time" or "always". Saigh et al (13) report on the failure of an electronic medical record tool to improve pain assessment documentation. In addition, having the patient spend more time interacting with an electronic or other assessment tool rather than in a 'live' clinical setting with a nurse or physician reduces the time of actual human interaction. While Roizen et al (14) have suggested that using an electronic questionnaire yields responses similar to a live interaction, the 0 to 10 pain intensity scale, whether live or electronic, clearly does not include any information on pain quality, timing, duration or functional impact, and does not constitute a pain assessment per se. More assessment must clearly follow. The ESAS scores are an indication of pain intensity, but do not provide information as to the underlying cause. Yennurajalingam et al (15) found that palliative care consultation actually increased many ESAS pain scores at the first visit relative to scores in the oncology clinic. Although this may be related, in part, to disease progression, it is also possible that patients feel more at ease rating their pain in the supportive care environment rather than in the oncology clinic, where disease treatment with chemotherapy or radiation therapy may have a higher priority. In summary, the question of how to ensure that a comprehensive or formal pain assessment is performed, either electronically or in person, following a high pain score on the screen remains to be answered.

The second concern is that of the difference in responses between malignant and non-cancer-related pain. On the surface, it appears that noncancer pain was not managed as actively as cancer-related pain. However, it must be acknowledged that the categories of clinical care 
responses we analyzed were directed more toward the management of acute or subacute cancer pain. For example, for chronic back pain, escalation of opioid medication may not be as appropriate as specific counselling and physical therapy, neither of which are readily available in oncology outpatient clinics or captured in our study. Confounding these data is the fact that patients may have both cancer- and noncancer-related pain; indeed, Valeberg et al (16) found that these patients are at greatest risk of undertreatment of pain. As well, oncologists may not feel responsible or competent for managing pain they see as unrelated to cancer, deferring instead to the family physician.

\section{Limitations}

One limitation to our study concerns the uncertainty regarding the link between the ESAS score and physician action. We cannot be sure that it is truly the screening tool that triggered the documented clinical care responses; it may well have been the direct verbal report of the patient and the physician may not have been aware of the ESAS result at all. This may also explain the reduced level of management of pain assumed to be non-cancer related because the patient may be less likely to mention it to the oncologist, especially when it is chronic and may have predated the cancer. Another limitation is that we did not assess the other components of the ESAS; concurrent high scores on several subscales may have triggered more active supportive care management plans including that of pain.

\section{Directions for future research and implications for practice}

Despite its inherent limitations, our study demonstrates a high prevalence of pain management plans when ESAS pain scores are used as a screening tool for severe pain. Several directions for future research are, nonetheless, evident. Further study in optimizing pain assessment,

\section{REFERENCES}

1. Cleeland C, Gonin R, Hatfield AK, et al. Pain and its treatment in outpatients with metastatic cancer. N Engl J Med 1994;330:592-6.

2. Shvartzman P, Friger M, Shani A, Barak F, Yoram C, Singer Y. Pain control in ambulatory cancer patients - can we do better? J Pain Symptom Manage 2003;26:716-22.

3. Deandrea S, Montanari M, Moja L, Apolone G. Prevalence of undertreatment in cancer pain. A review of published literature. Ann Oncol 2008;19:1985-91.

4. Mitera G, Zeiadin N, Kirou-Mauro A, et al. Retrospective assessment of cancer pain management in an outpatient palliative radiotherapy clinic using the Pain Management Index. J Pain Symptom Manage 2010;39:259-67.

5. Kirou-Mauro AM, Hird A, Wong J, et al. Has pain management in cancer patients with bone metastases improved? A seven-year review at an outpatient palliative radiotherapy clinic. J Pain Symptom Manage 2009:37:77-84.

6. Wells N, McDowell RM, Hendricks P, Dietrich MS, Murphy B. Cancer pain management in ambulatory care: Can we link assessment and action to outcomes? Support Care Cancer 2011:19:1865-71.

7. Trowbridge R, Dugan W, Jay SJ, et al. Determining the effectiveness of a clinical-practice intervention in improving the control of pain in outpatients with cancer. Acad Med 1997;72:798-800.

8. Cancer-related pain management. Toronto: Cancer Care Ontario, April 3, 2012 (Archived September 2011). Program in Evidencebased Care, Evidence-based Series No.: 16-2, Archived 2011.

9. Bruera E, Kuehn N, Miller MJ, Selmser P, MacMillan K. The Edmonton Symptom Assessment System (ESAS): A simple and working toward combining screening patient self-reports and more formal health care worker evaluations in practice remain priorities in symptom management. To further investigate the role of ESAS screening, a point-of-care questionnaire would have to be designed, enquiring of physicians whether they were aware of the ESAS score and whether they acted on it. In the time period after our study data were collected, the hospital changed the electronic patient record software so that pain scores $\geq 7$ of 10 would be highlighted in bright red. It would be interesting to examine what, if any, effect this highlighting may have with regard to the type of pain management plan that is instituted at the visit. Anecdotally, nurses are reporting that an increasing number of patients are refusing to fill out the ESAS scores on the previsit questionnaires because they perceive that the physician does not respond to, or mention, these scores. A postvisit questionnaire addressing this concern should be included in future studies. Finally, to further investigate the effectiveness of pain management plans, longitudinal review of changes in screening pain scores over time would be valuable and will be the subject of a future study of this patient population at our centre.

\section{CONCLUSION}

Our study suggests significant attention to pain management by oncologists for patients presenting with severe pain to outpatient oncology clinics. However, despite this, our study suggests that oncologists tend to focus more on actively managing cancer pain than pain believed to be unrelated to cancer; this finding should stimulate discussion in the cancer care community concerning the responsibility for pain management plans within the 'shared care model' of oncologist, family physician and pain management specialist.

method for the assessment of palliative care patients. J Palliat Care 1991;7:6-9.

10. Shelby D, Cascella A, Gardiner K, et al. A single set of numerical cutpoints to define moderate and severe symptoms for the Edmonton Symptom Assessment System. J Pain Symptom Manage 2010;39:241-9

11. Chisholm CD, Weaver CS, Whenmouth LF, Giles B, Brizendine EJ. A comparison of observed versus documented physician assessment and treatment of pain: The physician record does not reflect the reality. Ann Emerg Med 2008;52:383-89.

12. Bainbridge D, Seow H, Sussman J, et al. Multidisciplinary health care professionals' perceptions of the use and utility of a symptom assessment system for oncology patients. J Oncol Pract 2011;7:19-23.

13. Saigh O, Triola MM, Link RN. Brief report: Failure of an electronic medical record tool to improve pain assessment documentation. J Gen Intern Med 2006;21:185-88.

14. Roizen MF, Coalson D, Hayward RS, et al. Can patients use an automated questionnaire to define their current health status? Med Care 1992;30:74-84.

15. Yennurajalingam S, Kang JH, Hui D, Kang D-H, Kim SH, Bruera E. Clinical response to an outpatient palliative care consultation in patients with advanced cancer and cancer pain. J Pain Symptom Manage 2012;44:340-50

16. Valeberg BT, Rustøen T, Bjordal K, Hanestad BR, Paul S, Miaskowski C. Self-reported prevalence, etiology, and characteristics of pain in oncology outpatients. Eur J Pain 2008;12:582-90. 


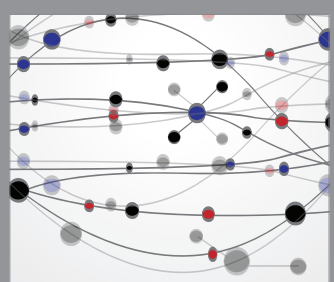

The Scientific World Journal
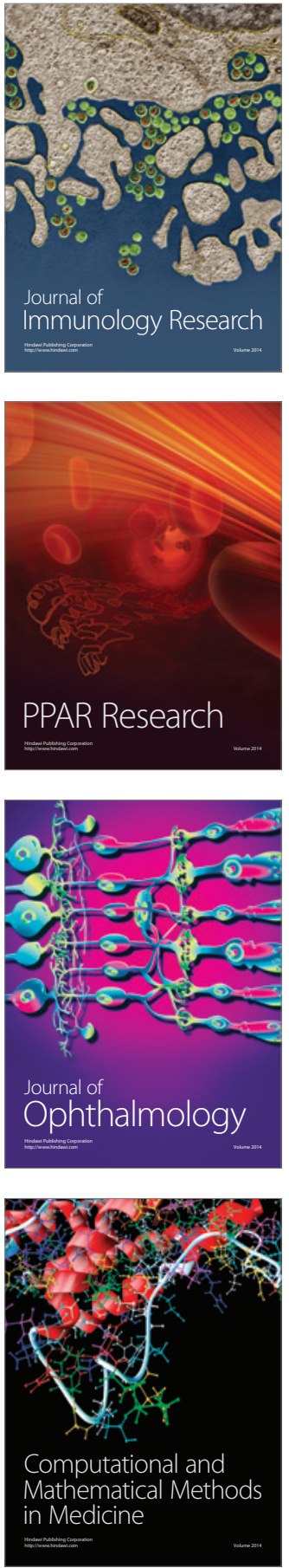

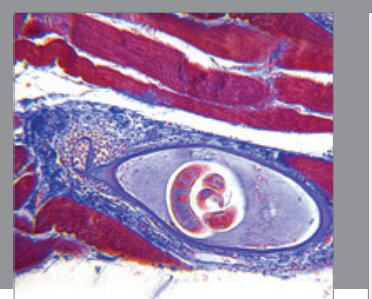

Gastroenterology Research and Practice

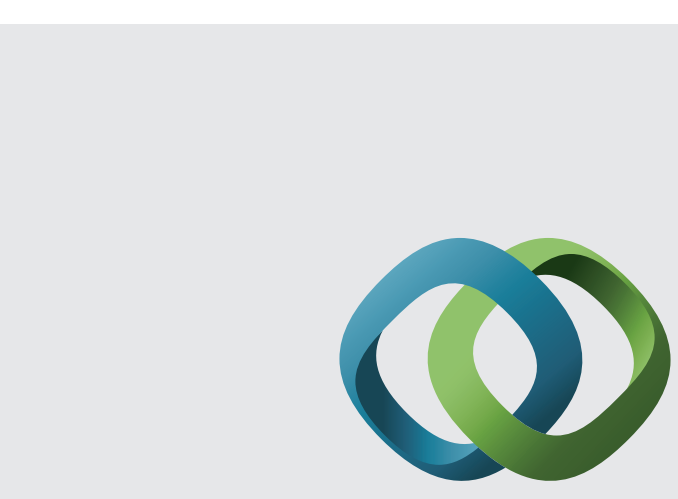

\section{Hindawi}

Submit your manuscripts at

http://www.hindawi.com
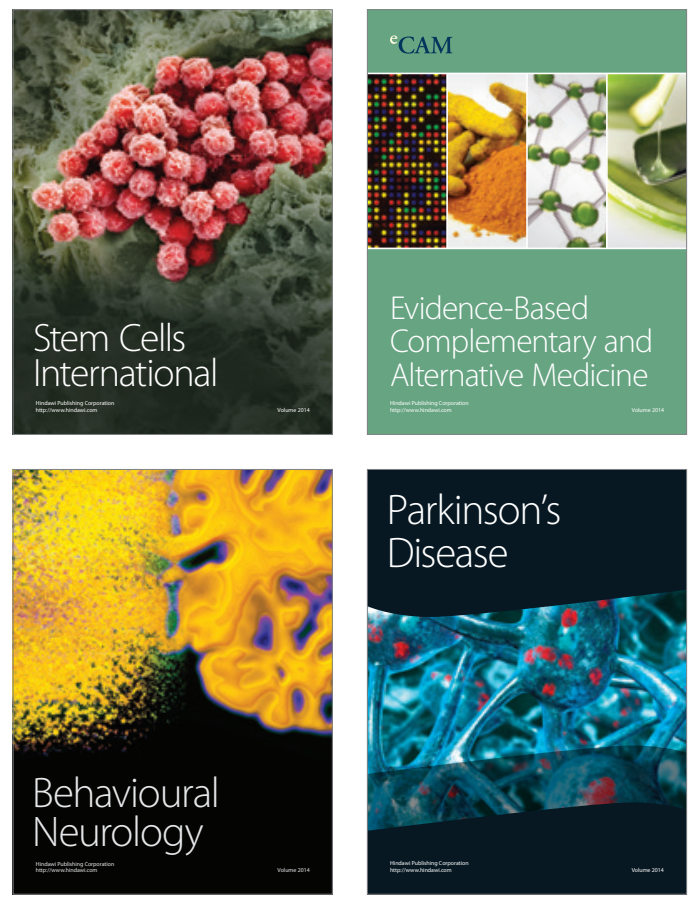
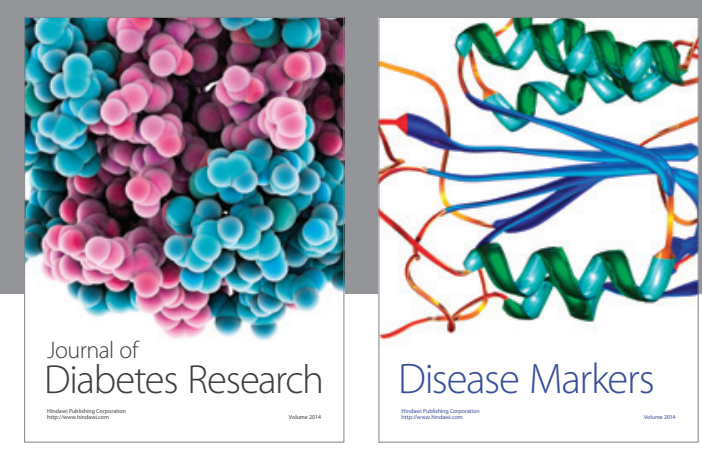

Disease Markers
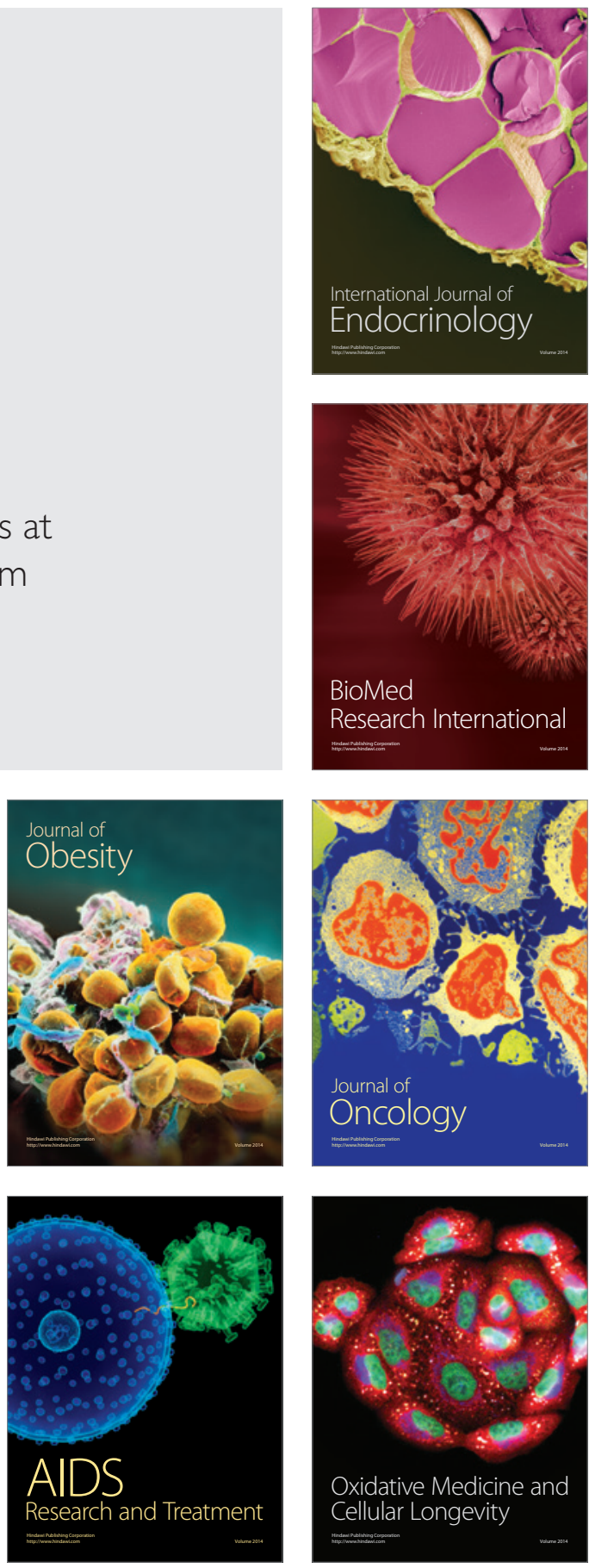